\title{
First Editorial
}

\author{
Daniel E. Graves $\mathbb{1}^{1}$
}

Received: 10 February 2021 / Accepted: 10 February 2021 / Published online: 4 March 2021

(c) The Author(s), under exclusive licence to International Spinal Cord Society 2021

Applying for the position of Editor-in-Chief was not easy. The idea of curating two journals covering a wide array of topics related to the spinal cord and the people who live with disability as a result of spinal cord injury is somewhat terrifying. However, for almost 30 years under the mentorship of Drs. Ronald G. Frankiewicz, R Edward Carter, and William H. Donovan, I have been preparing for this task. Because of their insights and generosity, it was easy to accept the challenge once the opportunity was offered. Also, thank you to the Editors of the Archives of Physical Medicine and Rehabilitation, Drs. Heinemann and Chan, the fifteen years I have been Section Editor served as a once in a lifetime learning opportunity.

My main goal with Spinal Cord and Spinal Cord Series and Cases is to increase the value of the journal for the scientific community, ISCoS members, and most importantly, people living with disabilities. Two main themes will predominate this first year of editorship for both journals: openness and transparency of the scientific process and systematic reporting of findings. The hard work of the previous editors is greatly appreciated. They instituted registration of clinical trials and recommending reporting guidelines. During this year we will be expanding the registration requirements to include systematic reviews prior to the commencement of work and expanding the requirement for using reporting guidelines. These actions will help the authors, reviewers and consumers of the research Published Spinal Cord and Spinal Cord Series and Cases. Increasing transparency and completeness of reporting will increase the number of publications that are cited in review articles and extend the life of an individual article.

One of the most exciting aspect of this position is opportunity of working with a large and talented group of researchers and clinicians who volunteer on the Editorial Boards. These members will be invited to discuss and recommend the policies to be instituted. We will be arranging meetings with both boards very soon.

It is with a profound sense of gratitude and with humility that I accept this appointment. I want to thank the ISCoS board for having the confidence in me to carry out this mission. Thank you to the members of the editorial boards for their tireless work, past and future. Finally, I want to thank the international community of people living with SCI related disability. You are our motivation to continue the immense task of finding scientific answers to real life problems and seeking a cure to alleviate the burden of disability.
Daniel E. Graves

spinalcord@comcast.net

1 Thomas Jefferson University, College of Rehabilitation Sciences, Philadelphia, PA, USA 